\title{
Genome Editing of the CYP1A1 Locus in iPSCs as a Platform to Map AHR Expression throughout Human Development
}

\author{
Brenden W. Smith, ${ }^{1,2}$ Elizabeth A. Stanford, ${ }^{1,2,3}$ David H. Sherr, ${ }^{3}$ and George J. Murphy ${ }^{1,2}$ \\ ${ }^{1}$ Section of Hematology and Oncology, Department of Medicine, Boston University School of Medicine, Boston, MA 02118, USA \\ ${ }^{2}$ Center for Regenerative Medicine (CReM), Boston University and Boston Medical Center, Boston, MA 02118, USA \\ ${ }^{3}$ Department of Environmental Health, Boston University School of Public Health, Boston, MA 02118, USA \\ Correspondence should be addressed to George J. Murphy; gjmurphy@bu.edu
}

Received 4 January 2016; Accepted 17 March 2016

Academic Editor: Fanny L. Casado

Copyright (C) 2016 Brenden W. Smith et al. This is an open access article distributed under the Creative Commons Attribution License, which permits unrestricted use, distribution, and reproduction in any medium, provided the original work is properly cited.

\begin{abstract}
The aryl hydrocarbon receptor (AHR) is a ligand activated transcription factor that increases the expression of detoxifying enzymes upon ligand stimulation. Recent studies now suggest that novel endogenous roles of the AHR exist throughout development. In an effort to create an optimized model system for the study of AHR signaling in several cellular lineages, we have employed a CRISPR/CAS9 genome editing strategy in induced pluripotent stem cells (iPSCs) to incorporate a reporter cassette at the transcription start site of one of its canonical targets, cytochrome P450 1A1 (CYP1A1). This cell line faithfully reports on CYP1A1 expression, with luciferase levels as its functional readout, when treated with an endogenous AHR ligand (FICZ) at escalating doses. iPSC-derived fibroblast-like cells respond to acute exposure to environmental and endogenous AHR ligands, and iPSCderived hepatocytes increase CYP1A1 in a similar manner to primary hepatocytes. This cell line is an important innovation that can be used to map AHR activity in discrete cellular subsets throughout developmental ontogeny. As further endogenous ligands are proposed, this line can be used to screen for safety and efficacy and can report on the ability of small molecules to regulate critical cellular processes by modulating the activity of the AHR.
\end{abstract}

\section{Introduction}

The aryl hydrocarbon receptor (AHR) has been studied for decades for its role in environmental toxin induced carcinogenesis $[1,2]$. A member of the Per/ARNT/SIM (PAS) family of basic helix-loop-helix (bHLH) transcription factors, the AHR is activated by small-molecule ligands that cause it to be disassociated from a cytoplasmic chaperone complex and translocated into the nucleus [3]. Upon nuclear translocation, the AHR dimerizes with the Aryl Hydrocarbon Receptor Nuclear Translocator (ARNT) and subsequently binds to conserved AHR response elements (AHREs) within the genome [4]. Through this pathway, the AHR affects the expression of multiple gene targets that contain AHREs in proximal regulatory regions $[5,6]$. Classic examples of AHR ligands include 2,3,7,8-tetrachlorodibenzodioxin (TCDD) [7], polycyclic aromatic hydrocarbons (PAHs), and polychlorinated biphenyls (PCBs) [8]. As part of an adaptive response to the presence of these carcinogens, the AHR significantly increases transcription of cytochrome p450 (CYP450) enzymes, specifically CYP1A1 [9] and CYP1B1 [10], that will contribute to the metabolism of these compounds into both toxic and nontoxic intermediates [11]. Concomitant with CYP450 activation, the AHR contributes to its own negative regulation by promoting transcription of the AHR Repressor (AHRR), a competitive inhibitor that prevents dimerization of the AHR:ARNT complex, causing free AHR molecules to be exported into the cytoplasm and subsequently degraded [12].

In the last 10 years, there has been a major paradigm shift following the demonstration that the AHR plays important physiological roles in the absence of environmental ligands [13]. Multiple studies suggest the AHR pathway is important in the development and function of the cardiovascular system [14-17] in the ahr knockout mouse without the requirement for experimental ligand exposure. Indeed, it is this same 
model organism that displays varied and diverse developmental phenotypes including, but not limited to, reduced liver size, increased portal tract fibrosis [18], decreased fertility [19, 20], a suspected resistance to neurotoxicity [21], and an impairment in the lymphocyte compartment [22]. AHR signaling has since been implicated in multiple aspects of human developmental ontogeny. Recent studies suggest that the AHR plays a critical role in human hematopoietic stem cell (HSC) differentiation [23], substantiating murine studies that show in vivo AHR modulation resulting in disruption of HSC growth, senescence, and migration [24]. Our own work reveals the AHR as a modulator of erythroid and megakaryocyte specification from a common bipotent progenitor [25], incorporating an endogenous ligand of the AHR (6formylindolo(3,2-b)carbazole or FICZ) to produce this result. Observed roles of the AHR in immunity and inflammation [26] as well as the discovery of novel endogenous AHR agonists [13] add to the overwhelming evidence that AHR signaling is endogenously regulated and crucially important throughout development. Compounded with evidence of regulatory cross talk with VEGF and TGF- $\beta$ pathways [27, 28 ], these studies seem to suggest that multiple roles of AHR signaling have yet to be discovered.

The advent of cellular reprogramming and genome editing has provided platforms to study signaling pathways in diverse and novel ways. Since their discovery in 2006 [29, 30], induced pluripotent stem cells (iPSCs) have been shown to functionally emulate embryonic stem cells (ESCs) [31, 32] by having the capacity to differentiate into all three germ layers of the developing embryo [29, 30]. iPSCs have been specified to multiple cellular lineages, including those derived from endoderm (liver [33-36], pancreas [37-39], and lung [40-42]), mesoderm (hematopoietic cells [25, 4348], heart [49-51], and kidney [52]), and ectoderm (neurons [53]). The flexibility of an iPSC-based system allows for the study of multiple tissue types. In this way, iPSCs stand to revolutionize the way we study human development, model disease, and eventually treat patients. Additionally, genome editing strategies have been widely used to create genetic knockouts, repair disease-causing mutations, and integrate reporter constructs [54]. Clustered regulatory interspersed short palindromic repeats (CRISPRs) have been identified as an element of bacterial adaptive immunity by which foreign DNA of invading species is incorporated into the host genome and subsequently used as a template upon which CRISPR associated (CAS) endonucleases bind and digest newly infected DNA [55]. The result is targeted cutting of double stranded DNA that is specific and highly efficient. Multiple groups have adapted this technology to mammalian systems to improve upon preexisting methodologies and have confirmed that this tool is highly accessible and amenable to targeted genome editing [56]. Despite the promise of this technology, there remains a paucity of studies that examine the AHR within the context of iPSC directed differentiation $[25,57]$ or incorporate CRISPR/CAS9 to employ genetic manipulation of AHR signaling [58]. Future work will help reveal the signaling dynamics and interregulatory cross talk of the AHR pathway in differentiated iPSCs within multiple cellular contexts.
Using a CRISPR/CAS9 system for genome editing, we have created an endogenous reporter of AHR activity in an iPSC line by targeting the CYP1A1 locus. CYP1A1 is a canonical target of AHR signaling, one that is widely used to report on AHR activity in multiple cell and tissue types in vivo and in vitro. As a result, its expression is commonly used as a functional output of AHR activity in the absence of ligand exposure. In this report, we show the utility of this cell line in its response to multiple agonists and antagonists and validate its function by observing AHR modulation in the context of both hematopoiesis and hepatic specification.

\section{Materials and Methods}

2.1. iPSC Generation and Maintenance. Induced pluripotent stem cells were generated as described previously [59, 60]. Briefly, $4 \mathrm{~mL}$ of human peripheral blood was collected into a BD Vacutainer CPT Cell Preparation Tube and centrifuged to produce a buffy coat containing peripheral blood mononuclear cells (PBMCs). The buffy coat was collected and PBMCs were cultured ex vivo for 9 days before being transduced with the STEMCCA lentiviral vector. At day 12 of culture, STEMCCA transduced PBMCs were plated onto mouse embryonic fibroblasts (MEFs) and cultured until roughly days 30-40, when fully formed iPSC colonies were identified and separately harvested. Following successive passages onto irradiated MEFs (R\&D, \#PSC001), colonies were adapted to matrigel-coated tissue culture dishes in the absence of a feeder cell layer. iPSCs were then cultured in mTESR1 media (StemCell Technologies, \#05850) for all further passages.

\subsection{Creation of CRISPR/CAS9 Targeted CYP1A1 Reporter} iPSCs. Targeting of the CYP1A1 locus was achieved by cotransfection of the plasmids described (Figure 1(a)). Confluent iPSC cultures were pretreated with $10 \mu \mathrm{M}$ Y-27632 (ROCK inhibitor) for 3 hours in mTESR1 medium. Cells were resuspended in $100 \mu \mathrm{L}$ of $\mathrm{P} 3$ solution (Lonza) and added to a cuvette for the Lonza 4D Nucleofector at a density of 5e6 cells per cuvette. $2 \mu \mathrm{g}$ of the CAS9 vector and $3 \mu \mathrm{g}$ of the Donor vector were added to the cell suspension and nucleofected using the CB-150 program. Immediately following nucleofection, cells were resuspended into fresh mTESR1 with $10 \mu \mathrm{M}$ Y-27632 and plated onto one $10 \mathrm{~cm}$ plate (pretreated with matrigel) and left at $37^{\circ}$ in a low oxygen $\left(5 \% \mathrm{O}_{2}\right)$ incubator. Cells were allowed to grow for 5 days before clones were selected for puromycin resistance by the addition of $0.7 \mu \mathrm{g} / \mathrm{mL}$ puromycin (ThermoFisher, \#A1113802). Colonies were harvested as they appeared in culture and were passaged and maintained separately before being screened by PCR for the integrated construct.

2.3. PCR and Sanger Sequencing. To validate proper targeting of the reporter construct to the CYP1A1 locus, two PCR products were amplified that flank the $5^{\prime}$ and $3^{\prime}$ ends of the reporter construct (resp.) and include elements of both the integrated cassette and the endogenous locus (Figure 1(c)). PCR was performed using recombinant Taq polymerase (ThermoFisher, \#10342) with primers 


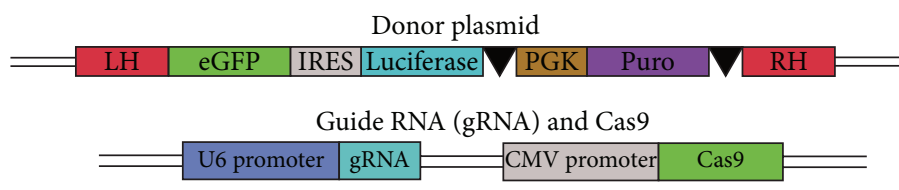

(a)

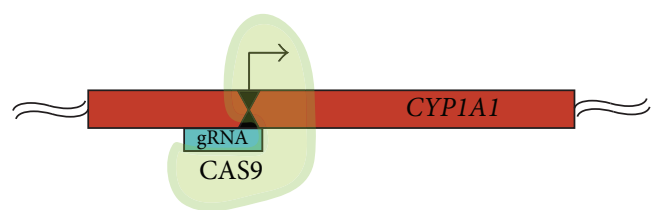

(b)

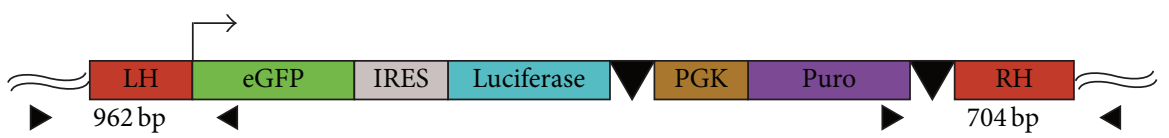

(c)

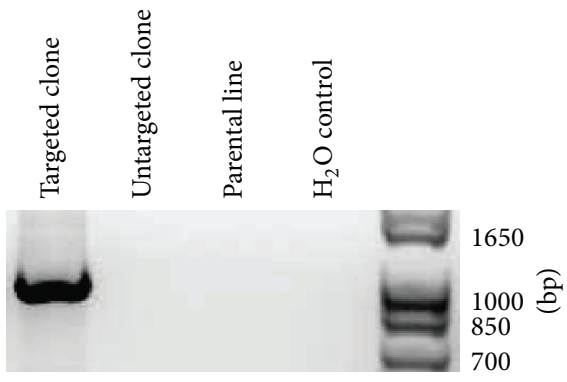

(d)

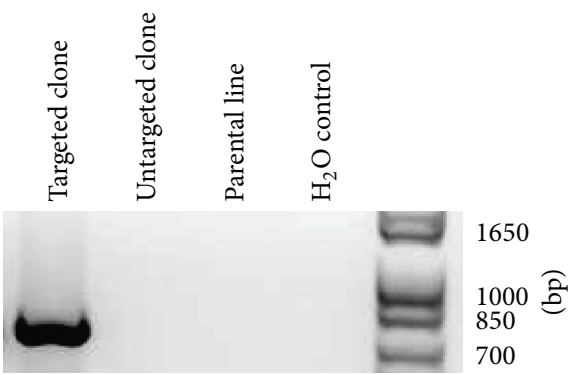

(e)

FIGURE 1: Construction and validation of CYP1A1 reporter iPSCs. (a) Two vectors were created to achieve CAS9 targeted digestion at the CYP1A1 transcription start site and homologous recombination of a reporter construct. The donor plasmid contains a cassette that includes eGFP and luciferase separated by an internal ribosome entry sequence (IRES). Directly downstream of these reporter elements is a puromycin resistance gene (Puro) driven by a constitutive promoter (PGK) and flanked by loxP sites (denoted by black arrowheads). This cassette is flanked by regions that are homologous to the CYP1A1 endogenous locus (Left Homology, LH; Right Homology, RH) to facilitate homologous recombination. The guide RNA (gRNA) and Cas9 were encoded on the same plasmid, each driven by a separate constitutive promoter (U6 and CMV, resp.). (b) An idealized schematic of Cas9 digestion at the transcription start site (denoted by black arrow) of the CYP1A1 locus. (c) The integrated reporter construct is expected to specifically target the transcription start site of CYP1A1, and a PCR strategy was employed that creates amplicons in the $5^{\prime}$ and $3^{\prime}$ flanking regions of the cassette that include elements from the reporter construct as well as endogenous regions that are not encoded by the donor plasmid. (d) The $5^{\prime}$ amplicon (expected size $=962 \mathrm{bp}$ ) was exclusively detected in a properly targeted iPSC clone. (e) The $3^{\prime}$ amplicon (expected size $=704 \mathrm{bp}$ ) also could not be amplified in untargeted clones or the parental iPSC line but was detected in a properly targeted iPSC clone.

for the $5^{\prime}$ amplicon (Forward: $5^{\prime}$-ggtgggatttcctgcatcct- $3^{\prime}$; Reverse: $5^{\prime}$-cttgtggccgtttacgtcg- $3^{\prime}$ ) and $3^{\prime}$ amplicon (Forward: $5^{\prime}$-cctgcaggatctgatcagataacttcg- $3^{\prime}$; Reverse: $5^{\prime}$-caggttgactaggctaagcagttcttg- $3^{\prime}$ ) in separate reactions. PCR products were resolved by agarose gel electrophoresis and were $962 \mathrm{bp}$ and $704 \mathrm{bp}$, respectively. Bands that appeared to be the proper size by electrophoresis were extracted and purified using the QiaQuick gel extraction kit (Qiagen, \#28704) and submitted for Sanger sequencing to Genewiz, Inc. Sequencing data, as well as all homology domain and guide RNA sequences, are available in Supplemental Figure 1 in Supplementary Material available online at http://dx.doi.org/10.1155/2016/2574152.

2.4. Generation of Hepatocyte-Like Cells from iPSCs. iPSC cultures were passaged using Gentle Cell Dissociation (GCD) Reagent (StemCell Technologies, \#07174) to obtain a single cell suspension and counted using a hemacytometer. Cells were passaged onto matrigel-coated tissue culture dishes at a cellular density of $3 \mathrm{e} 5$ per well of a standard 6-well plate. After 24 hours, mTESR1 was replaced by media provided by the STEMdiff Definitive Endoderm Kit (StemCell Technologies, \#05110) and cultured according to manufacturer's instructions for 5 days. At day 5, GCD was used to make a single cell suspension and the cells were passaged at a ratio of $1: 6$ onto matrigel-coated 6 well plates. The media for all subsequent days were an SFD base [61] with ascorbic acid $(50 \mu \mathrm{g} / \mathrm{mL})$ and monothioglycerol $(4.5 e-4 \mathrm{M})$. Media for days 5 and 6 included Activin A (50 ng/mL), BMP4 (10 ng/mL), FGF2 (10 ng/mL), and VEGF $(10 \mathrm{ng} / \mathrm{mL})$. The media for days 7-12, days 13-18, and days 19-25 were adapted directly from a previous manuscript [35]: days 712: BMP4 (50 ng/mL), FGF2 (10 ng/mL), VEGF (10 ng/mL), 
EGF (10 ng/mL), TGFa (20 ng/mL), HGF (100 ng/mL), and $0.1 \mu \mathrm{M}$ Dexamethasone; days 13-18: FGF2 (10 ng/mL), VEGF $(10 \mathrm{ng} / \mathrm{mL}), \mathrm{EGF}(10 \mathrm{ng} / \mathrm{mL}), \mathrm{HGF}(100 \mathrm{ng} / \mathrm{mL})$, Oncostatin $\mathrm{M}(20 \mathrm{ng} / \mathrm{mL})$, Vitamin $\mathrm{K}(6 \mu \mathrm{g} / \mathrm{mL}), 1.5 \mu \mathrm{M}$ gamma secretase inhibitor, $0.1 \mu \mathrm{M}$ Dexamethasone, and 1\% DMSO; days 19-25: HGF (100 ng/mL), Oncostatin M (20 ng/mL), Vitamin $\mathrm{K}(6 \mu \mathrm{g} / \mathrm{mL})$, and $0.1 \mu \mathrm{M}$ Dexamethasone. Cells were kept in a low oxygen $\left(5 \% \mathrm{O}_{2}\right)$ incubator throughout the differentiation.

2.5. Generation of Hematopoietic Progenitor Cells from iPSCs and Treatment with 6-Formylindolo(3,2-b)carbazole (FICZ). Hematopoietic progenitor cells were derived from induced pluripotent stem cells using our previously published protocol [25]. Briefly, iPSCs seeded on matrigel plates were exposed to cytokine conditions that promoted mesoderm specification, followed by a hemogenic endothelial-like phenotype, and, finally, hematopoietic progenitors that disadhered from the matrigel substrate and were dual positive for CD41 and CD235 (data not shown). At day 7 of the protocol (Supplemental Figure 2), cells were treated with escalating doses of FICZ, at a range of $10 e-8$ to $10 e-4 \mathrm{M}$, and kept in this condition for 5 days. Cells were harvested at day 12, at which point lysates were created for luciferase assays as well as RNA extraction and kept at $-80^{\circ} \mathrm{C}$.

2.6. RNA Extraction and Quantitative PCR. RNA was extracted using the RNeasy Mini Kit (Qiagen, \#74104). At the time of harvest, cells were washed with PBS and spun for 5 minutes at $300 \times \mathrm{g}$, and the pellet was collected in $350 \mu \mathrm{L}$ of Buffer RLT. RNA extraction proceeded according to manufacturer instructions. RNA was eluted into $30 \mu \mathrm{L}$ of endonuclease-free $\mathrm{H}_{2} \mathrm{O}$ and purified with DNAse using the DNA-free DNA Removal kit (ThermoFisher, \#AM1906). Once purified, $20 \mu \mathrm{L}$ of sample was used to generate cDNA using the High-Capacity cDNA Reverse Transcription Kit (Applied Biosystems, \#4368814). RNA samples were quantified using a NanoDrop Lite (Thermo Scientific) Spectrophotometer, and cDNA samples were diluted to $1 \mu \mathrm{g} / \mu \mathrm{L}$. Quantitative PCR was carried out using the Taqman Universal Master Mix (Thermo Scientific) and primers for CYP1A1 (Hs01054797_g1) and $\beta$-ACTIN (Hs99999903_ml) were used. Samples were run in triplicate and, where appropriate, were analyzed by Student's $t$-test to assess significance between groups.

2.7. Flow Cytometry. Flow cytometry was performed at days 5, 14, and 25 of hepatocyte specification. For day 5, $3 \mathrm{e} 5$ cells were stained per condition, and the C-KIT antibody (Biolegend, \#313206) and CXCR4 antibody (Invitrogen, \#MHCXCR404) were used at a concentration of $5 \mu \mathrm{L}$ per 1e6 cells. Staining was performed on ice for 30 minutes. For days 14 and 25, cells were fixed in $1.6 \%$ paraformaldehyde before staining. Primary antibodies for AAT (Santa Cruz, \#sc-59438) and FOXA1 (Santa Cruz, \#101058) were added at 1:100 ratio in Saponin Buffer (2\% FBS, 1x Permeabilization Wash Buffer (Biolegend, \#421002)) and incubated at room temperature for 30 minutes. Secondary antibodies for AAT (Jackson Immunoresearch, \#115-605-205) and FOXA1 (Jackson Immunoresearch, \#115-545-206) were added at a dilution of $1: 500$ and incubated at room temperature for 30 minutes. All samples were resuspended in PBS with 0.5\% BSA for analysis.

2.8. Luciferase Assays. To assess luciferase expression, cells were harvested and counted by hemacytometer to ensure 1e 5 cells per $20 \mu \mathrm{L}$ of $1 \mathrm{x}$ lysis buffer from the commercially available luciferase assay system (Promega, \#E1500). Upon sufficient lysis, samples were stored at $-80^{\circ} \mathrm{C}$ until all time points were collected. Samples were then thawed on ice and assayed by adding $20 \mu \mathrm{L}$ per well of a 96-well plate, followed by addition of $100 \mu \mathrm{L}$ of luciferase assay reagent (Promega) and immediate analysis of luminescence in a Tecan Infinite M1000 microplate reader.

2.9. Fibroblast Differentiation and Small Molecule Treatment. iPSCs were seeded on matrigel-coated 12-well plates at a density of $3 \mathrm{e} 5$ cells per well and left in mTESR medium for 24 hours. Fibroblast induction media (IMDM, 10\% FBS, 2 mM l-glutamine, and $100 \mu \mathrm{g} / \mathrm{mL}$ primocin (Invivogen, \#ant-pm1)) were added for 2 days, followed by small molecule treatment for exactly 24 hours before cells were harvested for luciferase and qPCR assays. Small molecule AHR modulators were added at the following concentrations: TCDD, $1 \mathrm{nM}$; $\mathrm{CH} 223191,10 \mu \mathrm{M}$; benzo[a]pyrene, $1 \mu \mathrm{M}$; benzo[e]pyrene, $1 \mu \mathrm{M}$; FICZ, $10 \mu \mathrm{M}$; indoxyl sulfate, $100 \mu \mathrm{M}$.

2.10. Image Capture and Analysis. All images were captured on a Nikon Eclipse TS100 microscope equipped with a Diagnostic Instruments, Inc., model 18.2 Color Masonic Camera. Images were processed using Adobe Illustrator software.

2.11. Statistical Analysis. Results are presented as mean \pm the standard error of the mean (SEM). Statistical significance was confirmed using the Student $t$-test as indicated.

\section{Results and Discussion}

3.1. Vector Design and Construction and Validation of a CYP1A1 Reporter iPSC Line. To create an endogenous reporter of AHR activity in an iPSC line, a CRISPR/CAS9 system was engineered to target the CYP1A1 locus. A plasmid was created that expresses a reporter cassette of enhanced green fluorescent protein (eGFP) and firefly luciferase bifurcated by an internal ribosomal entry sequence (IRES) to allow for each reporter gene to be expressed on the same transcript (Figure 1(a)). Downstream of this cassette is a puromycin resistance gene (PURO) driven by a constitutive promoter for murine phosphoglycerate kinase (PGK) to allow for antibiotic selection. This reporter sequence does not include a $5^{\prime}$ regulatory region but rather is flanked by homology arms that facilitate recombination directly downstream of the CYP1A1 transcription start site in the endogenous locus (Supplemental Figure 1B). Using this strategy, reporter expression is exclusively driven by the CYP1A1 promoter, a regulatory region that includes 10 distinct AHR response elements (AHREs) [62]. A guide RNA sequence (gRNA) was developed using a publically available web resource (http://crispr.mit.edu/) 
created and distributed by the Zhang Lab at the Massachusetts Institute of Technology [63]. The guide RNA shares sequence homology with a 23-base-pair region exactly 8 base pairs downstream of the CYP1A1 start codon $\left(5^{\prime}\right.$ CCCAATCTCCATGTCGGCCACGG-3 ${ }^{\prime}$ ) that includes a 3base-pair protospacer adjacent motif (PAM) sequence that is necessary for CAS9 binding (Figure 1(b); Supplemental Figure $1 \mathrm{~B}$ ). The guide RNA and CAS9 coding regions were included on the same plasmid, separate from the plasmid containing the reporter construct, each with a dedicated constitutive promoter (Figure 1(a)).

Cotransfection of the two engineered plasmids produced a series of puromycin resistant clones which were then screened for the inserted reporter sequence within the CYP1A1 locus. Validation was accomplished by a PCR strategy that creates two distinct amplicons at the flanking regions of the integrated cassette. Using this strategy, each amplified region contains elements of the CYP1A1 endogenous locus that is not included in the homology arms as well as elements of the donor sequence (Figure 1(c)). Successful PCR amplification of these regions can only be achieved in properly targeted clones (Figures 1(d) and 1(e)) and Sanger sequencing confirms that each amplicon includes genomic regions of the CYP1A1 locus as well as elements from the donor construct (Supplemental Figure 1A).

3.2. CYP1A1 Reporter iPSCs Respond to FICZ in a DoseDependent Manner. To achieve functional validation of the properly targeted clone, we used a previously published, directed differentiation protocol for the production of hematopoietic progenitors of the megakaryocyte and erythroid lineages [25]. Our previous work revealed that activation of the AHR pathway with 6-formylindolo(3,2b)carbazole (FICZ) in this population causes exponential expansion and increased viability in culture [25]. Having proven this population's responsiveness to AHR agonism, we treated hematopoietic progenitors derived from a CYP1A1 targeted clone with escalating doses of FICZ for 5 days. FICZ treatment increased transcript expression of CYP1A1 in a dose-dependent manner, and this result was observed in both the parental iPSC line and the CYP1A1 targeted clone (Supplemental Figure 2A). These cultures were also assayed for luciferase expression, and unlike CYP1A1 transcript expression, only the CYP1A1 targeted line displayed luciferase bioluminescence that increased significantly with each successive FICZ dose (Supplemental Figure 2B). This work confirms that the CRISPR/CAS9 targeted clone faithfully reports on AHR activation through a functional output of luciferase expression.

3.3. Mapping of AHR Activity throughout Human Hepatocyte Specification Using CYP1A1 Targeted iPSCs. To fully utilize the CYP1A1 targeted iPSC line, we differentiated these cells towards the hepatocyte lineage in order to showcase the potential of this reagent to provide a temporal map of AHR activation in a variety of cellular contexts. Multiple studies have reported on the AHR response to environmental ligands in primary liver and have displayed a baseline level of CYPIA1 expression even in the absence of toxin exposure [64]. Thus, in order to confirm the utility of this cell line, we sought to recapitulate these results in an in vitro context using a previously described protocol for directed differentiation to hepatocyte specification $[35,36]$. Using this strategy, we successfully produced cells with definitive endodermal markers (CXCR4 and CKIT) after 5 days of differentiation and proceeded to incorporate a cytokine cocktail including FGF2 and Activin A to produce early hepatocyte progenitors at day 14, as indicated by observed dual positivity for Alpha 1 Antitrypsin (AAT) and FoxA1 (Figure 2(a)). Cultures were subsequently exposed to a specified media containing Hepatic Growth Factor (HGF) and Oncostatin M, and at day 25 , the AAT+/FoxA1+ population had increased substantially (63.7\%) (Figure 2(a)). Micrographs taken at days 5, 14, and 25 of differentiation show the progressive change in cellular morphology of these cells as they formed a homogenous 2D monolayer (day 5) followed by a heterogenous population where polygonal hepatic-like cells began to emerge (day 14) and, finally, an adherent cellular layer dominated by granular, polygonal cells with distinct, sinusoidal-like boundaries (day 25) (Figure 2(b)). The CYP1A1 reporter clone was differentiated in parallel with the parental iPSC line, and luciferasedependent bioluminescence was assayed at each time point throughout the hepatic differentiation. Undifferentiated cells (day 0) as well as CXCR4+/CKIT+ definitive endoderm (day 5) produced low levels of CYP1A1-driven luciferase, but a marked increase in luciferase expression was observed in hepatocyte progenitors (day 14) and, more significantly, early hepatocytes (day 25) (Figure 2(c)). Interestingly, the discrepancy seen between these two final time points is highly correlated to the relative abundance of AAT+/FoxA1+ dual positive cells within these cultures, suggesting that AHR activation occurs exclusively in this discrete population. The ability of CYP1A1 targeted iPSCs to faithfully report on patterns of activation previously reported in primary cells is an early indication of the utility of this cell line in mimicking in vivo ontogeny and providing an easily accessible model system upon which to study this highly ubiquitous pathway.

3.4. CYP1A1 Reporter iPSC-Derived Fibroblast-Like Cells Respond to Putative AHR Ligands. With the evolution of the AHR field, culminating in the description of endogenous roles of the AHR in the absence of classical, environmentally derived ligands, the value of an iPSC clone with the capacity to report on AHR activation is dependent upon its sensitivity to multiple small molecule compounds previously shown to affect AHR signaling [65-67]. To assess the ability of the CYP1A1 targeted cell line to respond to exogenous and proposed endogenous AHR ligands, we ran a comprehensive chemical screen and assayed for luciferasedependent luminescence at 24 hours after dosing. Due to the observed lack of AHR dependent luciferase expression in the undifferentiated state (Figure 2(c)) we exposed iPSCs to a simplified media over the course of two days that quickly altered the cellular morphology to a fibroblast-like appearance (Figure 3(a)). These cells had detectable luminescence in the naivve (untreated) condition (Figure 3(b)), whereas undifferentiated cells had an indistinguishable expression 


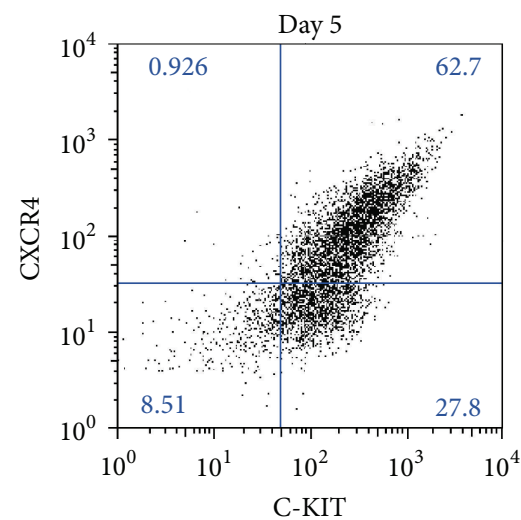

Day 5

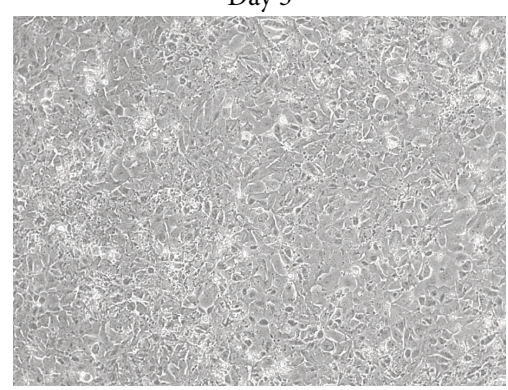

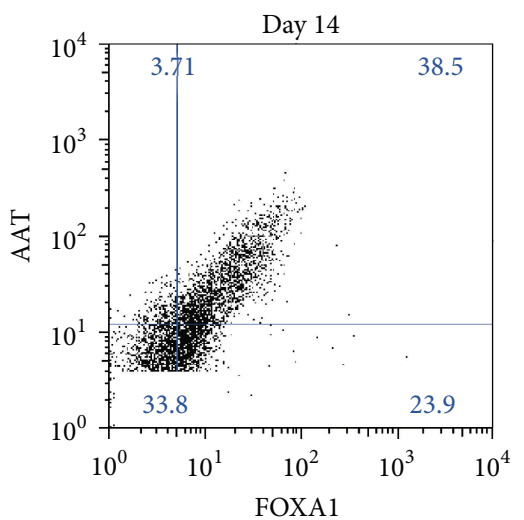

(a)
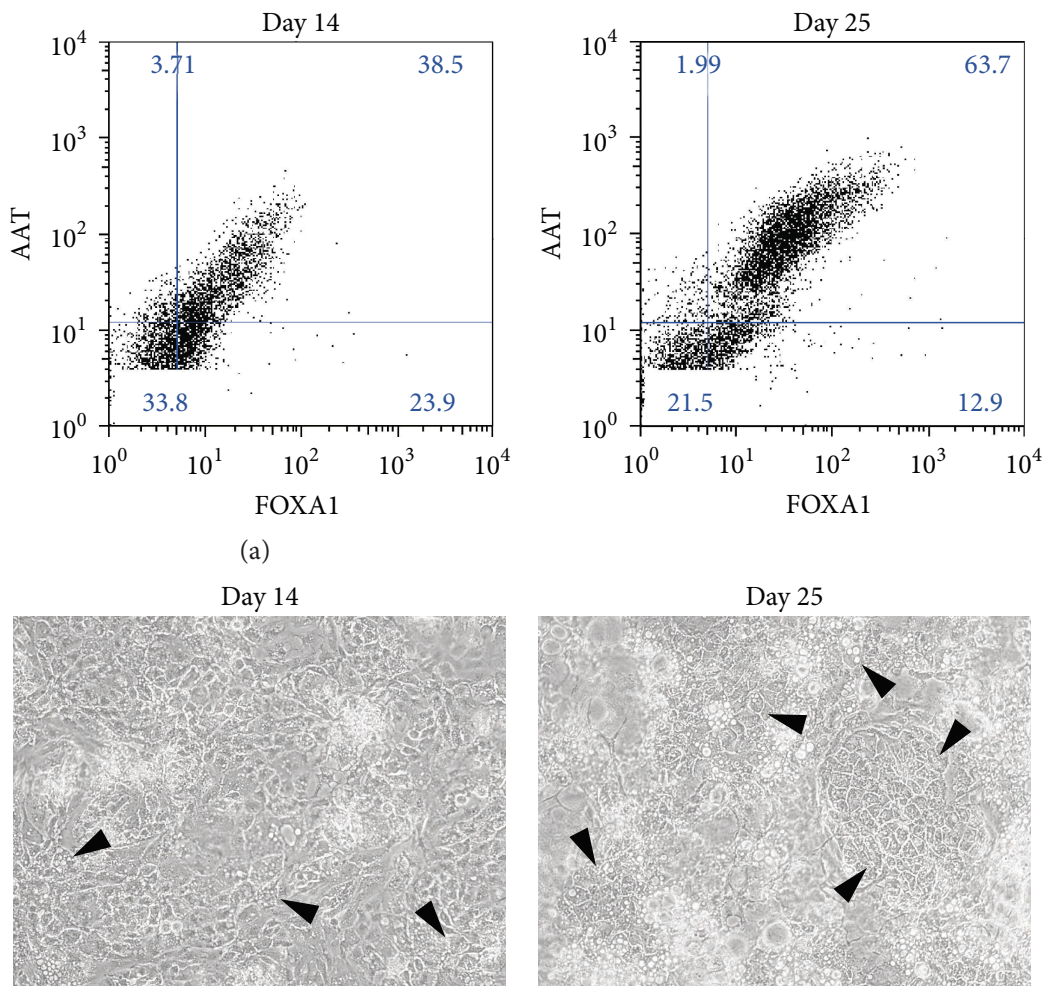

Day 25

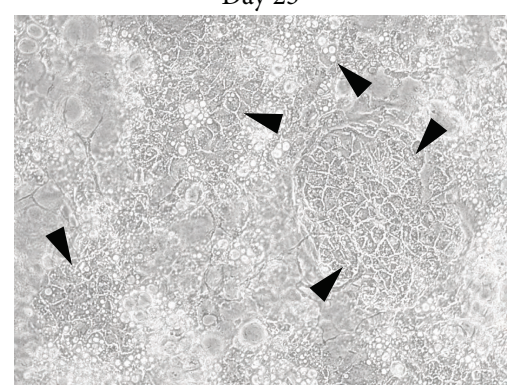

(b)

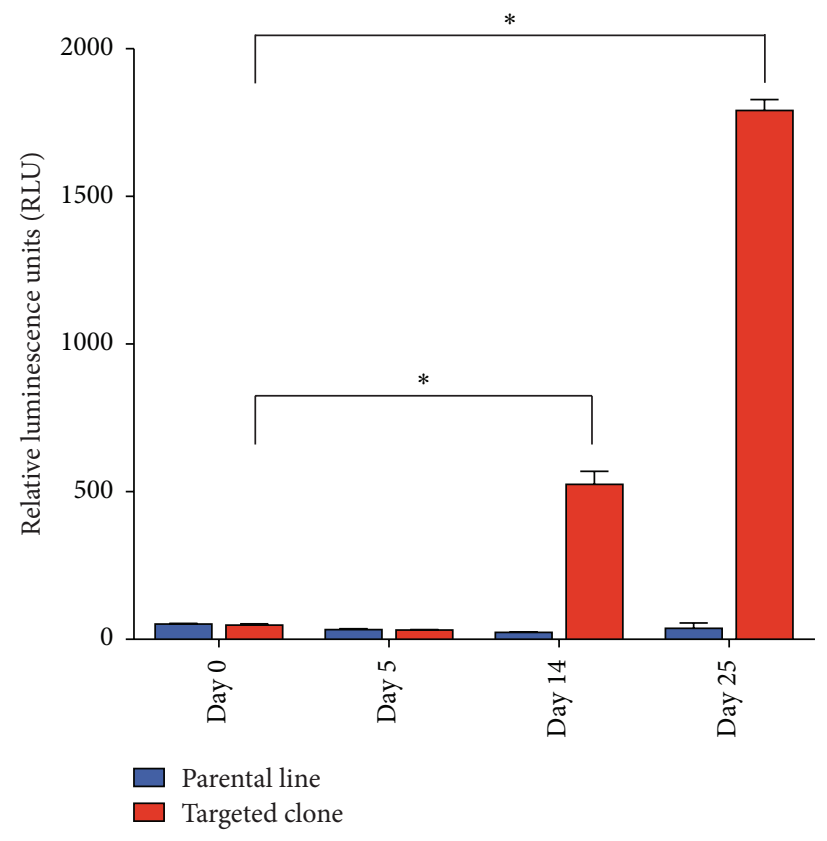

(c)

FIGURE 2: Hepatocyte specification yields luciferase expression in cells derived from CYP1A1 reporter iPSCs. (a) iPSCs were differentiated towards CXCR4+/C-KIT+ definitive endoderm (day 5) followed by FOXA1+/AAT+ hepatic progenitors (day 14) that grew in number and were the majority of the culture by day 25. (b) Micrographs show homogenous morphology of definitive endoderm cultures (day 5), but by day 14, hepatic-like cells begin to emerge (denoted by black arrowheads) and are observed more frequently by day 25 . (c) Concomitant with hepatic specification, luciferase levels significantly increase $\left(N=3,{ }^{*} \mathrm{P}<0.0005\right.$, Student's $t$-test). 


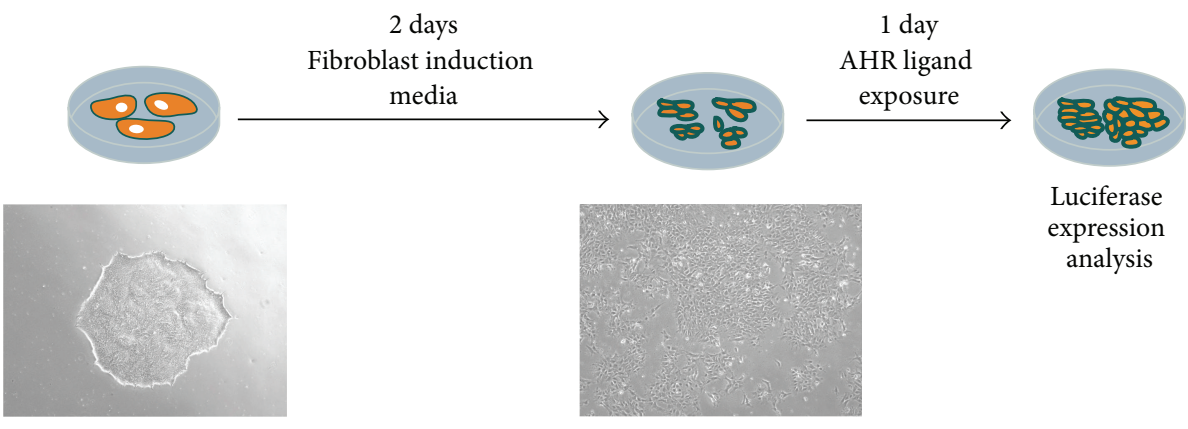

(a)

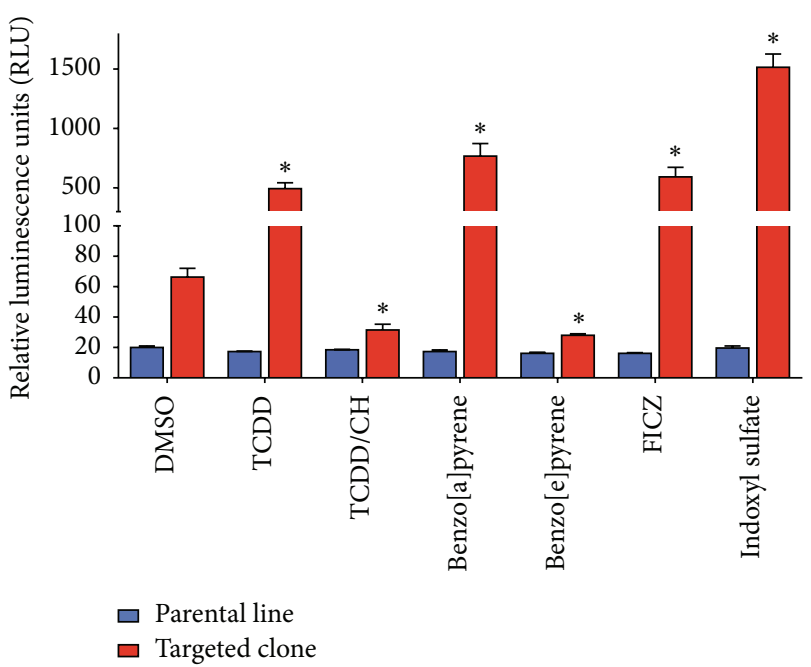

(b)

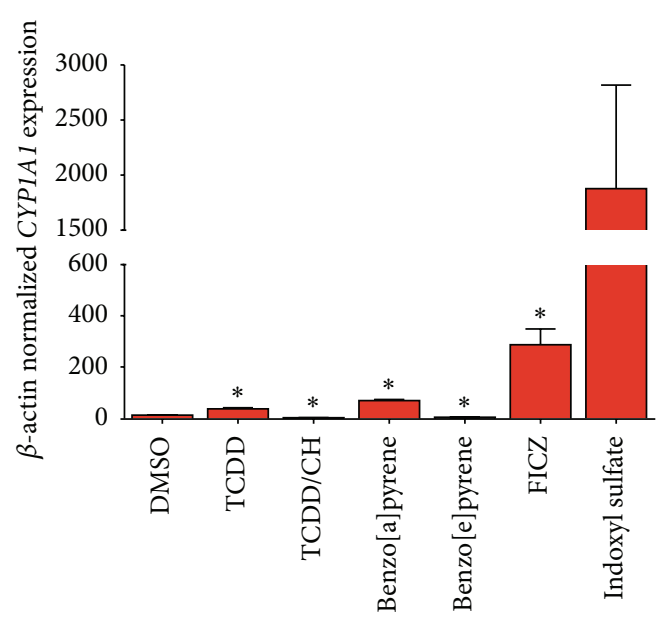

ㅁargeted clone

(c)

FIGURE 3: Acute exposure to AHR ligands causes a predictable response in CYP1A1 reporter iPSCs. (a) Fibroblast-like cells were differentiated from CYP1A1 iPSCs over the course of 2 days using fibroblast induction media. A compendium of AHR ligands were then added to the cultures for 24 hours before cells were harvested for further analysis. (b) Luciferase expression analysis reveals patterns of activation and inhibition of the CYPIA1 reporter (targeted clone) as a response to agonist and antagonist treatment. Significance was established by Student's $t$-test for each condition compared to the DMSO control condition $\left({ }^{*} P<0.01, N=3\right)$ (c) Transcript level expression of endogenous CYP1A1 in the targeted clone showed similar patterns of modulated expression that positively correlated to luciferase output. Significance was established by Student's $t$-test for each condition compared to the DMSO control condition $\left({ }^{*} P<0.02, N=3\right)$.

profile to that of the parental iPSC line (Figure 2(c); day 0 time point). Our chemical screen incorporated known environmental ligands, including TCDD and benzo[a]pyrene, as well as endogenous agonists' indoxyl sulfate and FICZ, and a potent AHR antagonist, $\mathrm{CH} 223191(\mathrm{CH})$. Treatment with DMSO alone established the basal levels of luciferase output, and TCDD induced a significant response that was completely occluded by the presence of $\mathrm{CH} 223191$ (Figure 3(b); TCDD/CH condition). Both of these compounds are known to affect gene expression in an AHR dependent fashion, giving further credence to the specificity of this AHR reporter system. Further, the polycyclic aromatic hydrocarbon benzo[a]pyrene induced AHR activity while benzo[e]pyrene, a structurally similar compound previously shown to have very little affinity for AHR in the cytoplasm [68], actually seemed to inhibit activity relative to the vehicle control. Additionally, the tryptophan derivatives indoxyl sulfate and 6-formylindolo(3,2-b)carbazole (FICZ) also proved efficacious in this model system. Finally, CYP1A1 gene expression was assessed and found to be modulated in a similar pattern to that of luciferase expression (Figure 3(c)), further substantiating the hypothesis that luciferase expression reports directly on AHR activation.

\section{Conclusions}

Multiple bioassays have been developed to study AHR signaling in distinct cellular subtypes. These systems' utility has mainly been in the identification of environmental ligands [69] and, recently, the discovery of proposed endogenous ligands that range from the tryptophan derivates FICZ $[70,71]$ and indoxyl sulfate [72] to bilirubin, a natural product of heme catabolism $[73,74]$ and the arachidonic acid metabolites prostaglandin G [75] and lipoxin A4 [76]. Perhaps the most widely utilized experimental reporter is the pGudLuc vector, of which multiple iterations have been reported in the literature [69]. This vector was created by incorporating a 482-base-pair segment of the murine CYP1A1 
promoter with 4 AHREs (also known as Dioxin Response Elements, or DREs) within the mouse mammary tumor virus (MMTV) promoter, with luciferase expression as the functional readout. Since its inception [77], this reagent has been optimized for better stability [69] and used by many groups to assess ligand responsiveness in immortalized cell models [78, 79].

The endogenous reporter of AHR activity described in this work represents a significant technological advancement that is highly specific and accessible to researchers with various expertise. Unlike immortalized cell lines with stable transfection of pGudLuc, this iPSC line has a targeted integrant directly downstream of the CYP1A1 transcription start site. Despite observations in the literature of off-target CRISPR/CAS9 cutting [80], the functional data presented herein substantiates our hypothesis that little to no offtarget integration of the reporter construct exists in this particular case. We hypothesize, then, that this reporter line is isogenic to an in-house iPSC control and can be efficiently differentiated to multiple cellular lineages. Transcript level expression of CYP1A1 in the targeted line upon FICZ treatment (Supplemental Figure 2) proves that endogenous CYP1A1 is not knocked-out as a result of genomic integration, making it likely that the reporter construct is hemizygously expressed. This would indicate that this clone has a single integrant in the exact genomic location that AHR:ARNT dimers naturally modulate CYP1A1 gene expression. This system avoids random integration of an artificial promoter driven construct that could be expressed in multiple genomic locations, affecting endogenous gene expression in unknown ways. It also uses the entire CYP1A1 promoter to drive expression, utilizing potentially complex interactions and gene expression profiles dependent on distal cis elements that cannot be conveyed by transfection of reporter plasmids. TCDD exposure, for example, is known to affect local chromatin structure in promoting endogenous CYP1A1 expression [81] and selective ligands may alter AHR:ARNT dimer binding, causing AHRE-independent control of the CYP1A1 promoter [82]. Indeed, our finding that benzo[e]pyrene inhibits CYP1A1 expression in fibroblast-like cells (Figure 3) contradicts reports of its lack of affinity towards the AHR and warrants further investigation. Thus, this cell line will be critically important in future studies that implicate novel small molecule compounds as AHR modulators.

iPSC technology continues to be an attractive avenue for basic science to achieve clinically relevant applications. Less than a decade after their inception, iPSCs are being used as a source of cellular therapeutics [82] and have undergone successful gene correction in lines created from primary cells of patient populations [83]. Now, there is the potential to turn iPSC-derived cultures into drug screening tools that can provide early indices of safety and efficacy before patient populations are exposed [84-87]. Given the widely reported role of AHR signaling in hepatotoxicity [88] and carcinogenesis [89], our reporter iPSC line is an optimal tool to reveal potential toxicity of compounds of interest in preclinical phases of development.

As the full extent of AHR pathway dynamics is discovered and the mechanisms of endogenous ligand regulation dominate the literature, it will become paramount to map AHR activation throughout all phases of development. Induced pluripotent stem cells provide an invaluable tool by which to derive distinct cellular subtypes of all three germ layers, and the CYP1A1 reporter line presented in this work can provide an output of AHR activity that can be observed in every experimental context. Differentiation strategies that mimic in vivo ontogeny have the potential to serve as "temporal maps" of AHR activity throughout cytokine driven progression of cells to a distinct lineage. To this end, cellular fate decisions of progenitor populations can be correlated to AHR expression, and terminally differentiated cells can be assayed for AHR activity relative to their specification and function. Multiple novel roles of AHR signaling as well as the identity and dynamics of endogenous ligands have yet to be discovered; the reporter iPSC line described in this work will be invaluable to these studies moving forward.

\section{Competing Interests}

The authors declare that there is no conflict of interests regarding the publication of this paper.

\section{Acknowledgments}

George J. Murphy is supported by NIH U01 HL10744301, and David H. Sherr is supported by NIH P01-ES11624, P42ES007381, and the Art beCAUSE Breast Cancer Foundation.

\section{References}

[1] T. V. Beischlag, J. L. Morales, B. D. Hollingshead, and G. H. Perdew, "The aryl hydrocarbon receptor complex and the control of gene expression," Critical Reviews in Eukaryotic Gene Expression, vol. 18, no. 3, pp. 207-250, 2008.

[2] B. C. Spink, S. Pang, B. T. Pentecost, and D. C. Spink, "Induction of cytochrome P450 1B1 in MDA-MB-231 human breast cancer cells by non-ortho-substituted polychlorinated biphenyls," Toxicology in Vitro, vol. 16, no. 6, pp. 695-704, 2002.

[3] B. E. McIntosh, J. B. Hogenesch, and C. A. Bradfield, "Mammalian Per-Arnt-Sim proteins in environmental adaptation," Annual Review of Physiology, vol. 72, pp. 625-645, 2010.

[4] H. I. Swanson, "DNA binding and protein interactions of the AHR/ARNT heterodimer that facilitate gene activation," Chemico-Biological Interactions, vol. 141, no. 1-2, pp. 63-76, 2002.

[5] T. Matikainen, G. I. Perez, A. Jurisicova et al., "Aromatic hydrocarbon receptor-driven Bax gene expression is required for premature ovarian failure caused by biohazardous environmental chemicals," Nature Genetics, vol. 28, no. 4, pp. 355-360, 2001.

[6] S. Ke, A. B. Rabson, J. F. Germino, M. A. Gallo, and Y. Tian, "Mechanism of suppression of cytochrome P-450 1A1 expression by tumor necrosis factor- $\alpha$ and lipopolysaccharide," Journal of Biological Chemistry, vol. 276, no. 43, pp. 3963839644, 2001.

[7] J. Mimura and Y. Fujii-Kuriyama, "Functional role of AhR in the expression of toxic effects by TCDD," Biochimica et Biophysica Acta: General Subjects, vol. 1619, no. 3, pp. 263-268, 2003. 
[8] S. A. Kafafi, H. Y. Afeefy, A. H. Ali, H. K. Said, and G. A. Kafafi, "Binding of polychlorinated biphenyls to the aryl hydrocarbon receptor," Environmental Health Perspectives, vol. 101, no. 5, pp. 422-428, 1993.

[9] K. Kawajiri, J. Watanabe, O. Gotoh, Y. Tagashira, K. Sogawa, and Y. Fujii-Kuriyama, "Structure and drug inducibility of the human cytochrome P-450c gene," European Journal of Biochemistry, vol. 159, no. 2, pp. 219-225, 1986.

[10] Y. M. Tang, Y.-Y. P. Wo, J. Stewart et al., "Isolation and characterization of the human cytochrome p450 CYP1B1 gene," Journal of Biological Chemistry, vol. 271, no. 45, pp. 2832428330, 1996.

[11] R.-E. Go, K.-A. Hwang, and K.-C. Choi, "Cytochrome P450 1 family and cancers," The Journal of Steroid Biochemistry and Molecular Biology, vol. 147, pp. 24-30, 2015.

[12] R. S. Pollenz, "The mechanism of AH receptor protein downregulation (degradation) and its impact on $\mathrm{AH}$ receptormediated gene regulation," Chemico-Biological Interactions, vol. 141, no. 1-2, pp. 41-61, 2002.

[13] M. S. Denison and S. R. Nagy, "Activation of the aryl hydrocarbon receptor by structurally diverse exogenous and endogenous chemicals," Annual Review of Pharmacology and Toxicology, vol. 43, pp. 309-334, 2003.

[14] E. A. Thackaberry, D. M. Gabaldon, M. K. Walker, and S. M. Smith, "Aryl hydrocarbon receptor null mice develop cardiac hypertrophy and increased hypoxia-inducible factor- $1 \alpha$ in the absence of cardiac hypoxia," Cardiovascular Toxicology, vol. 2, no. 4, pp. 263-273, 2002.

[15] G. P. Lahvis, S. L. Lindell, R. S. Thomas et al., "Portosystemic shunting and persistent fetal vascular structures in aryl hydrocarbon receptor-deficient mice," Proceedings of the National Academy of Sciences of the United States of America, vol. 97, no. 19, pp. 10442-10447, 2000.

[16] A. Vasquez, N. Atallah-Yunes, F. C. Smith et al., "A role for the aryl hydrocarbon receptor in cardiac physiology and function as demonstrated by AhR knockout mice," Cardiovascular Toxicology, vol. 3, no. 2, pp. 153-163, 2003.

[17] N. Zhang, "The role of endogenous aryl hydrocarbon receptor signaling in cardiovascular physiology," Journal of Cardiovascular Disease Research, vol. 2, no. 2, pp. 91-95, 2011.

[18] P. Fernandez-Salguero, T. Pineau, D. M. Hilbert et al., "Immune system impairment and hepatic fibrosis in mice lacking the dioxin-binding Ah receptor," Science, vol. 268, no. 5211, pp. 722726, 1995.

[19] B. D. Abbott, J. E. Schmid, J. A. Pitt et al., "Adverse reproductive outcomes in the transgenic Ah receptor-deficient mouse," Toxicology and Applied Pharmacology, vol. 155, no. 1, pp. 62-70, 1999.

[20] T. Baba, J. Mimura, N. Nakamura et al., "Intrinsic function of the aryl hydrocarbon (dioxin) receptor as a key factor in female reproduction," Molecular and Cellular Biology, vol. 25, no. 22, pp. 10040-10051, 2005.

[21] L. García-Lara, F. Pérez-Severiano, D. González-Esquivel, G. Elizondo, and J. Segovia, "Absence of aryl hydrocarbon receptors increases endogenous kynurenic acid levels and protects mouse brain against excitotoxic insult and oxidative stress," Journal of Neuroscience Research, vol. 93, no. 9, pp. 1423-1433, 2015.

[22] C. Esser, "The immune phenotype of AhR null mouse mutants: not a simple mirror of xenobiotic receptor over-activation," Biochemical Pharmacology, vol. 77, no. 4, pp. 597-607, 2009.
[23] A. E. Boitano, J. Wang, R. Romeo et al., "Aryl hydrocarbon receptor antagonists promote the expansion of human hematopoietic stem cells," Science, vol. 329, no. 5997, pp. 1345$1348,2010$.

[24] T. A. Gasiewicz, K. P. Singh, and J. A. Bennett, “The Ah receptor in stem cell cycling, regulation, and quiescence," Annals of the New York Academy of Sciences, vol. 1310, no. 1, pp. 44-50, 2014.

[25] B. W. Smith, S. S. Rozelle, A. Leung et al., "The aryl hydrocarbon receptor directs hematopoietic progenitor cell expansion and differentiation," Blood, vol. 122, no. 3, pp. 376-385, 2013.

[26] M. Cella and M. Colonna, "Aryl hydrocarbon receptor: linking environment to immunity," Seminars in Immunology, vol. 27, no. 5, pp. 310-314, 2015.

[27] H. L. Goel and A. M. Mercurio, "VEGF targets the tumour cell," Nature Reviews Cancer, vol. 13, no. 12, pp. 871-882, 2013.

[28] M. Pickup, S. Novitskiy, and H. L. Moses, "The roles of TGF $\beta$ in the tumour microenvironment," Nature Reviews Cancer, vol. 13, no. 11, pp. 788-799, 2013.

[29] K. Takahashi and S. Yamanaka, "Induction of pluripotent stem cells from mouse embryonic and adult fibroblast cultures by defined factors," Cell, vol. 126, no. 4, pp. 663-676, 2006.

[30] K. Takahashi, K. Tanabe, M. Ohnuki et al., "Induction of pluripotent stem cells from adult human fibroblasts by defined factors," Cell, vol. 131, no. 5, pp. 861-872, 2007.

[31] A. Kuzmenkin, H. Liang, G. Xu et al., "Functional characterization of cardiomyocytes derived from murine induced pluripotent stem cells in vitro," The FASEB Journal, vol. 23, no. 12, pp. 4168-4180, 2009.

[32] D. A. Robinton and G. Q. Daley, "The promise of induced pluripotent stem cells in research and therapy," Nature, vol. 481, no. 7381, pp. 295-305, 2012.

[33] A. Ghodsizadeh, A. Taei, M. Totonchi et al., "Generation of liver disease-specific induced pluripotent stem cells along with efficient differentiation to functional hepatocyte-like cells," Stem Cell Reviews and Reports, vol. 6, no. 4, pp. 622-632, 2010.

[34] A. Leung, S. K. Nah, W. Reid et al., "Induced pluripotent stem cell modeling of multisystemic, hereditary transthyretin amyloidosis," Stem Cell Reports, vol. 1, no. 5, pp. 451-463, 2013.

[35] A. A. Wilson, L. Ying, M. Liesa et al., "Emergence of a stage-dependent human liver disease signature with directed differentiation of $\alpha-1$ antitrypsin-deficient iPS cells," Stem Cell Reports, vol. 4, no. 5, pp. 873-885, 2015.

[36] A. Leung and G. J. Murphy, "Multisystemic disease modeling of liver-derived protein folding disorders using induced pluripotent stem cells (iPSCs)," in Patient-Specific Induced Pluripotent Stem Cell Models, vol. 1353 of Methods in Molecular Biology, pp. 261-270, Springer, 2016.

[37] D. Zhang, W. Jiang, M. Liu et al., "Highly efficient differentiation of human ES cells and iPS cells into mature pancreatic insulinproducing cells," Cell Research, vol. 19, no. 4, pp. 429-438, 2009.

[38] Z. Alipio, W. Liao, E. J. Roemer et al., "Reversal of hyperglycemia in diabetic mouse models using induced-pluripotent stem (iPS)-derived pancreatic $\beta$-like cells," Proceedings of the National Academy of Sciences of the United States of America, vol. 107, no. 30, pp. 13426-13431, 2010.

[39] T. Kaitsuka, H. Noguchi, N. Shiraki et al., "Generation of functional insulin-producing cells from mouse embryonic stem cells through $804 \mathrm{G}$ cell-derived extracellular matrix and protein transduction of transcription factors," Stem Cells Translational Medicine, vol. 3, no. 1, pp. 114-127, 2014. 
[40] M. Ghaedi, E. A. Calle, J. J. Mendez et al., "Human iPS cell-derived alveolar epithelium repopulates lung extracellular matrix," The Journal of Clinical Investigation, vol. 123, no. 11, pp. 4950-4962, 2013.

[41] S. E. Gilpin, X. Ren, T. Okamoto et al., "Enhanced lung epithelial specification of human induced pluripotent stem cells on decellularized lung matrix," Annals of Thoracic Surgery, vol. 98, no. 5, pp. 1721-1729, 2014.

[42] A. L. Firth, T. Menon, G. S. Parker et al., "Functional gene correction for cystic fibrosis in lung epithelial cells generated from patient iPSCs," Cell Reports, vol. 12, no. 9, pp. 1385-1390, 2015.

[43] C. Lengerke, M. Grauer, N. I. Niebuhr et al., "Hematopoietic development from human induced pluripotent stem cells," Annals of the New York Academy of Sciences, vol. 1176, pp. 219227, 2009.

[44] A. E. Grigoriadis, M. Kennedy, A. Bozec et al., "Directed differentiation of hematopoietic precursors and functional osteoclasts from human ES and iPS cells," Blood, vol. 115, no. 14, pp. 2769-2776, 2010.

[45] L. Carpenter, R. Malladi, C.-T. Yang et al., "Human induced pluripotent stem cells are capable of B-cell lymphopoiesis," Blood, vol. 117, no. 15, pp. 4008-4011, 2011.

[46] C.-J. Chang, K. Mitra, M. Koya et al., "Production of embryonic and fetal-like red blood cells from human induced pluripotent stem cells," PLoS ONE, vol. 6, no. 10, Article ID e25761, 2011.

[47] N. Takayama and K. Eto, "In vitro generation of megakaryocytes and platelets from human embryonic stem cells and induced pluripotent stem cells," Methods in Molecular Biology, vol. 788, pp. 205-217, 2012.

[48] S. Hirata, N. Takayama, R. Jono-Ohnishi et al., "Congenital amegakaryocytic thrombocytopenia iPS cells exhibit defective MPL-mediated signaling," Journal of Clinical Investigation, vol. 123, no. 9, pp. 3802-3814, 2013.

[49] K. Schenke-Layland, K. E. Rhodes, E. Angelis et al., "Reprogrammed mouse fibroblasts differentiate into cells of the cardiovascular and hematopoietic lineages," Stem Cells, vol. 26, no. 6, pp. 1537-1546, 2008.

[50] J. Zhang, G. F. Wilson, A. G. Soerens et al., "Functional cardiomyocytes derived from human induced pluripotent stem cells," Circulation Research, vol. 104, no. 4, pp. e30-e41, 2009.

[51] I. Germanguz, O. Sedan, N. Zeevi-Levin et al., "Molecular characterization and functional properties of cardiomyocytes derived from human inducible pluripotent stem cells," Journal of Cellular and Molecular Medicine, vol. 15, no. 1, pp. 38-51, 2011.

[52] Q. Li, S.-F. Tian, Y. Guo et al., "Transplantation of induced pluripotent stem cell-derived renal stem cells improved acute kidney injury," Cell and Bioscience, vol. 5, article 45, 2015.

[53] N. L. Payne, A. Sylvain, C. O’Brien, D. Herszfeld, G. Sun, and C. C. A. Bernard, "Application of human induced pluripotent stem cells for modeling and treating neurodegenerative diseases," New Biotechnology, vol. 32, no. 1, pp. 212-228, 2015.

[54] M. Li, K. Suzuki, N. Y. Kim, G.-H. Liu, and J. C. I. Belmonte, "A cut above the rest: targeted genome editing technologies in human pluripotent stem cells," The Journal of Biological Chemistry, vol. 289, no. 8, pp. 4594-4599, 2014.

[55] B. Wiedenheft, S. H. Sternberg, and J. A. Doudna, "RNA-guided genetic silencing systems in bacteria and archaea," Nature, vol. 482, no. 7385, pp. 331-338, 2012.

[56] Y. F. S. Seah, C. A. EL Farran, T. Warrier, J. Xu, and Y.-H. Loh, "Induced pluripotency and gene editing in disease modelling: perspectives and challenges," International Journal of Molecular Sciences, vol. 16, no. 12, pp. 28614-28634, 2015.

[57] W. Hu, J. Zhao, and G. Pei, "Activation of aryl hydrocarbon receptor $(\mathrm{AhR})$ by tranilast, an anti-allergy drug, promotes miR-302 expression and cell reprogramming," The Journal of Biological Chemistry, vol. 288, no. 32, pp. 22972-22984, 2013.

[58] N. Aluru, S. I. Karchner, D. G. Franks, D. Nacci, D. Champlin, and M. E. Hahn, "Targeted mutagenesis of aryl hydrocarbon receptor $2 \mathrm{a}$ and $2 \mathrm{~b}$ genes in Atlantic killifish (Fundulus heteroclitus)," Aquatic Toxicology, vol. 158, pp. 192-201, 2015.

[59] C. A. Sommer, M. Stadtfeld, G. J. Murphy, K. Hochedlinger, D. N. Kotton, and G. Mostoslavsky, "Induced pluripotent stem cell generation using a single lentiviral stem cell cassette," Stem Cells, vol. 27, no. 3, pp. 543-549, 2009.

[60] A. G. Sommer, S. S. Rozelle, S. Sullivan et al., "Generation of human induced pluripotent stem cells from peripheral blood using the STEMCCA lentiviral vector," Journal of Visualized Experiments, no. 68, article e4327, 2012.

[61] V. Gouon-Evans, L. Boussemart, P. Gadue et al., "BMP-4 is required for hepatic specification of mouse embryonic stem cell-derived definitive endoderm," Nature Biotechnology, vol. 24, no. 11, pp. 1402-1411, 2006.

[62] S. Kress, J. Reichert, and M. Schwarz, "Functional analysis of the human cytochrome P4501A1 (CYP1A1) gene enhancer," European Journal of Biochemistry, vol. 258, no. 2, pp. 803-812, 1998.

[63] L. Cong and F. Zhang, "Genome engineering using CRISPRCas9 system," Methods in Molecular Biology, vol. 1239, pp. 197217, 2015.

[64] M. J. Santostefano, V. M. Richardson, N. J. Walker et al., "Dosedependent localization of TCDD in isolated centrilobular and periportal hepatocytes," Toxicological Sciences, vol. 52, no. 1, pp. 9-19, 1999.

[65] I. A. Murray, A. D. Patterson, and G. H. Perdew, "Aryl hydrocarbon receptor ligands in cancer: friend and foe," Nature Reviews Cancer, vol. 14, no. 12, pp. 801-814, 2014.

[66] P. B. Busbee, M. Rouse, M. Nagarkatti, and P. S. Nagarkatti, "Use of natural AhR ligands as potential therapeutic modalities against inflammatory disorders," Nutrition Reviews, vol. 71, no. 6, pp. 353-369, 2013.

[67] L. Stejskalova, Z. Dvorak, and P. Pavek, "Endogenous and exogenous ligands of aryl hydrocarbon receptor: current state of art," Current Drug Metabolism, vol. 12, no. 2, pp. 198-212, 2011.

[68] T. Shimada, K. Inoue, Y. Suzuki et al., "Arylhydrocarbon receptor-dependent induction of liver and lung cytochromes $\mathrm{P} 4501 \mathrm{~A} 1,1 \mathrm{~A} 2$, and $1 \mathrm{~B} 1$ by polycyclic aromatic hydrocarbons and polychlorinated biphenyls in genetically engineered C57BL/6J mice," Carcinogenesis, vol. 23, no. 7, pp. 1199-1207, 2002.

[69] D. Han, S. R. Nagy, and M. S. Denison, "Comparison of recombinant cell bioassays for the detection of Ah receptor agonists," BioFactors, vol. 20, no. 1, pp. 11-22, 2004.

[70] R. Nuti, M. Gargaro, D. Matino et al., "Ligand Binding and functional selectivity of L-tryptophan metabolites at the mouse aryl hydrocarbon receptor (mAhR)," Journal of Chemical Information and Modeling, vol. 54, no. 12, pp. 3373-3383, 2014.

[71] Y.-D. Wei, H. Helleberg, U. Rannug, and A. Rannug, "Rapid and transient induction of CYP1A1 gene expression in human cells by the tryptophan photoproduct 6-formylindolo[3,2b]carbazole," Chemico-Biological Interactions, vol. 110, no. 1-2, pp. 39-55, 1998. 
[72] J. C. Schroeder, B. C. DiNatale, I. A. Murray et al., "The uremic toxin 3-indoxyl sulfate is a potent endogenous agonist for the human aryl hydrocarbon receptor," Biochemistry, vol. 49, no. 2, pp. 393-400, 2010.

[73] D. Phelan, G. M. Winter, W. J. Rogers, J. C. Lam, and M. S. Denison, "Activation of the Ah receptor signal transduction pathway by bilirubin and biliverdin," Archives of Biochemistry and Biophysics, vol. 357, no. 1, pp. 155-163, 1998.

[74] H. Togawa, S. Shinkai, and T. Mizutani, "Induction of human UGT1A1 by bilirubin through AhR dependent pathway," Drug Metabolism Letters, vol. 2, no. 4, pp. 231-237, 2008.

[75] S. D. Seidel, G. M. Winters, W. J. Rogers et al., "Activation of the Ah receptor signaling pathway by prostaglandins," Journal of Biochemical and Molecular Toxicology, vol. 15, no. 4, pp. 187196, 2001.

[76] F. S. Machado, J. E. Johndrow, L. Esper et al., "Antiinflammatory actions of lipoxin A4 and aspirin-triggered lipoxin are SOCS-2 dependent," Nature Medicine, vol. 12, no. 3, pp. 330-334, 2006.

[77] P. M. Garrison, K. Tullis, J. M. M. J. G. Aarts, A. Brouwer, J. P. Giesy, and M. S. Denison, "Species-specific recombinant cell lines as bioassay systems for the detection of 2,3,7,8tetrachlorodibenzo-p-dioxin-like chemicals," Fundamental and Applied Toxicology, vol. 30, no. 2, pp. 194-203, 1996.

[78] T. J. Murray, X. Yang, and D. H. Sherr, "Growth of a human mammary tumor cell line is blocked by galangin, a naturally occurring bioflavonoid, and is accompanied by downregulation of cyclins D3, E, and A," Breast Cancer Research, vol. 8, no. 2, article R17, 2006.

[79] L. K. Gustavsson, N. Klee, H. Olsman, H. Hollert, and M. Engwall, "Fate of Ah receptor agonists during biological treatment of an industrial sludge containing explosives and pharmaceutical residues," Environmental Science and Pollution Research, vol. 11, no. 6, pp. 379-387, 2004.

[80] X.-H. Zhang, L. Y. Tee, X.-G. Wang, Q.-S. Huang, and S.$\mathrm{H}$. Yang, "Off-target effects in CRISPR/Cas9-mediated genome engineering," Molecular Therapy Nucleic Acids, vol. 4, article e264, 2015.

[81] S. T. Okino and J. P. Whitlock Jr., "Dioxin induces localized, graded changes in chromatin structure: implications for Cyp1A1 gene transcription," Molecular and Cellular Biology, vol. 15, no. 7, pp. 3714-3721, 1995.

[82] D. E. DeGroot and M. S. Denison, "Nucleotide specificity of DNA binding of the aryl hydrocarbon receptor: ARNT complex is unaffected by ligand structure," Toxicological Sciences, vol. 137, no. 1, pp. 102-113, 2014.

[83] P. Simara, J. A. Motl, and D. S. Kaufman, "Pluripotent stem cells and gene therapy," Translational Research, vol. 161, no. 4, pp. 284-292, 2013.

[84] N. Zhang, B. J. Bailus, K. L. Ring, and L. M. Ellerby, "iPSC-based drug screening for Huntington's disease," Brain Research, 2015.

[85] E. Tzatzalos, O. J. Abilez, P. Shukla, and J. C. Wu, "Engineered heart tissues and induced pluripotent stem cells: macro- and microstructures for disease modeling, drug screening, and translational studies," Advanced Drug Delivery Reviews, vol. 96, pp. 234-244, 2016.

[86] Y. Z. Xie and R. X. Zhang, "Neurodegenerative diseases in a dish: the promise of iPSC technology in disease modeling and therapeutic discovery," Neurological Sciences, vol. 36, no. 1, pp. 21-27, 2014.
[87] V. Rosa, W. S. Toh, T. Cao, and W. Shim, "Inducing pluripotency for disease modeling, drug development and craniofacial applications," Expert Opinion on Biological Therapy, vol. 14, no. 9, pp. 1233-1240, 2014.

[88] G. Zollner, M. Wagner, and M. Trauner, "Nuclear receptors as drug targets in cholestasis and drug-induced hepatotoxicity," Pharmacology and Therapeutics, vol. 126, no. 3, pp. 228-243, 2010.

[89] S. Safe, S.-O. Lee, and U.-H. Jin, "Role of the aryl hydrocarbon receptor in carcinogenesis and potential as a drug target," Toxicological Sciences, vol. 135, no. 1, pp. 1-16, 2013. 

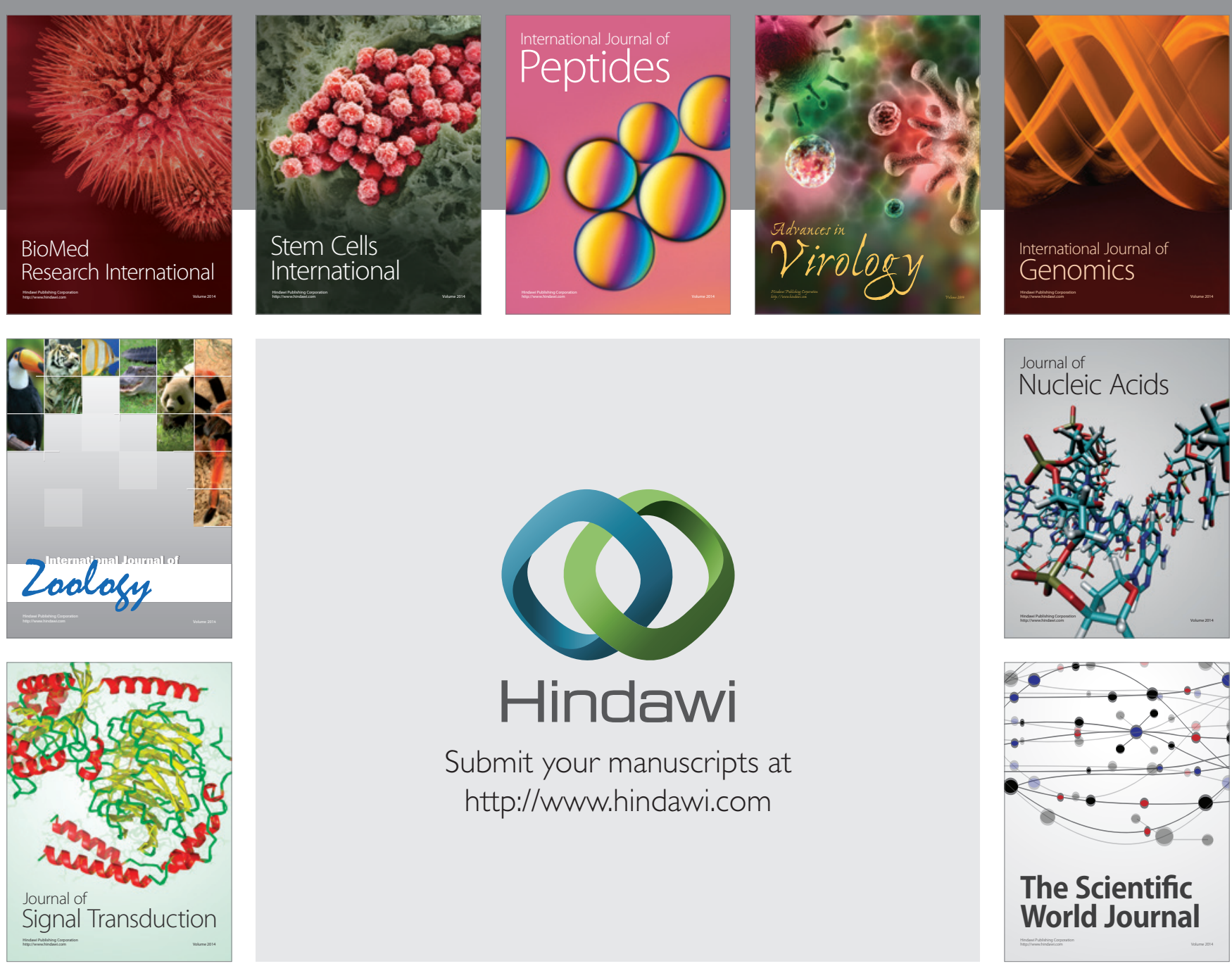

Submit your manuscripts at

http://www.hindawi.com
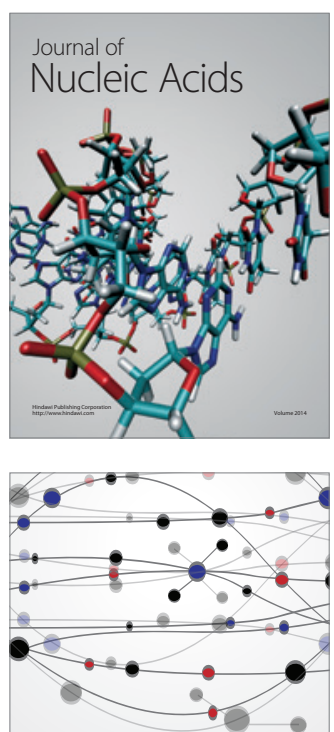

The Scientific World Journal
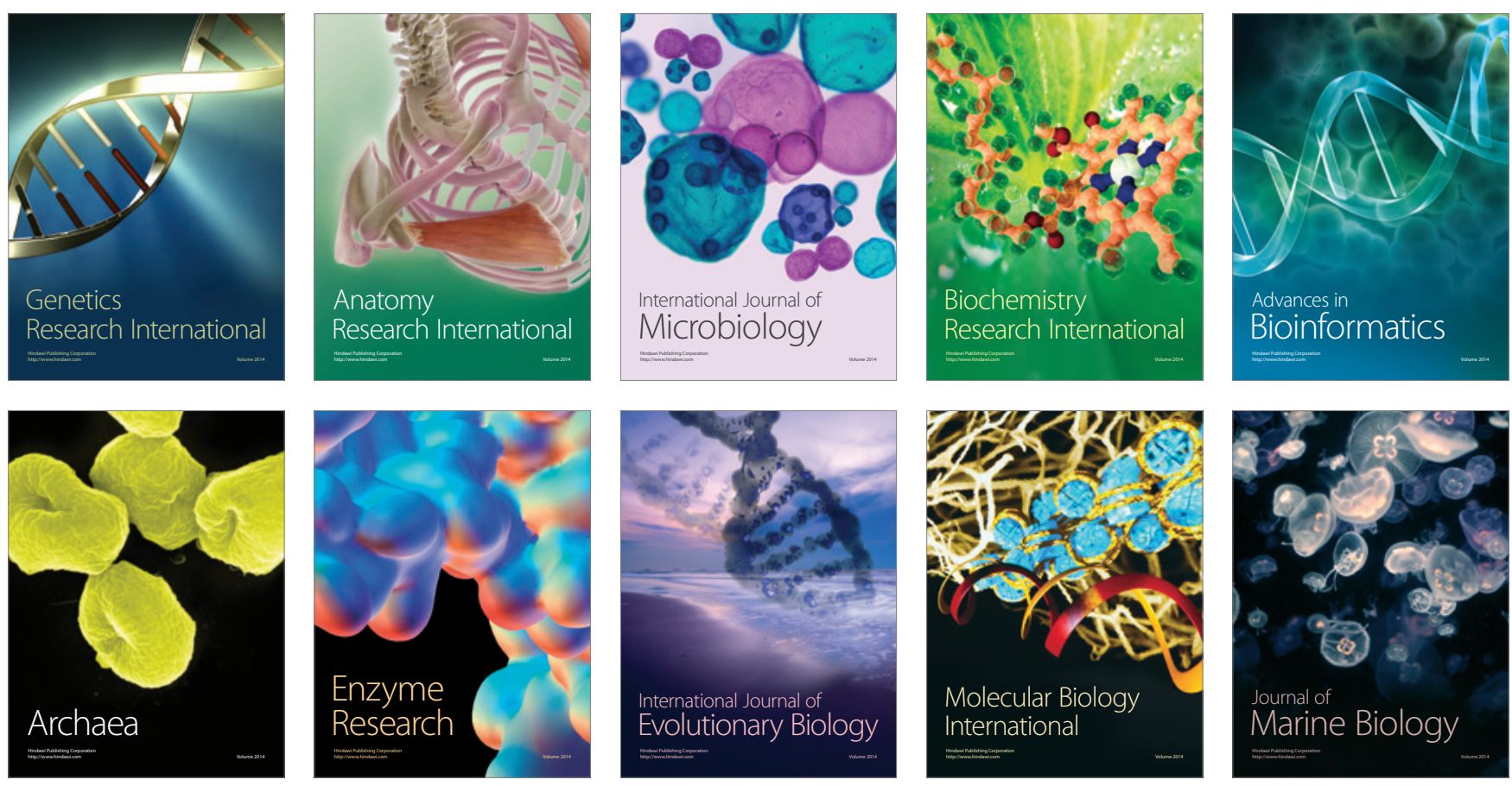